\title{
Application of Mobile Learning System in Phonetics Teaching
}

\author{
Jing XIAO \\ Foreign Languages Department, Zhuhai College, Jilin University, China
}

Yong LUO

Electrical and Information College, Jinan University, China

\begin{abstract}
Phonetics is an essential part of foreign language learning. With the help of mobile communication technologies, mobile learning has developed into a new mode of learning. This paper investigates the effectiveness of mobile learning system on phonetics teaching. Fourteen-week experiment proves combining mobile learning with classroom phonetics teaching has enhanced students' phonetic awareness and effectively improved their pronunciation level. The questionnaire reveals first-year students lack a sufficient knowledge on mobile learning; teachers' instruction and supervision are needed before and during the activities.
\end{abstract}

KEYWORD: Mobile learning system; Phonetics teaching; Phonetics training

\section{INTRODUCTION}

In a language, speech sound is the most important medium in oral communication. Good pronunciation can enhance the ability expressing thoughts or ideas, promote better understanding and efficient communication. Unfortunately, plenty of Chinese college students' English pronunciation is far from satisfactory. Owing to the over-crowded classroom, fewer teaching hours and constraints of the traditional teaching setting, phonetic teaching has long been neglected in college English education.

With the rapid development of mobile communications technology, a new learning model--Mobile Learning (M-learning) takes into shape. Mobile technology is changing the way we live and it is beginning to change the way we learn. The increased access to mobile technological devices, the availability of support systems and the need for communication has paved the way for learning to be available anytime and everywhere (Desmond Keegan, 2000). This paper attempts to figure out whether mobile learning integrated in traditional phonetics teaching can effectively improve the pedagogical effectiveness.

\section{MOBILE LEARNING AND MOBILE ASSISTED LANGUAGE LEARNING}

Research on mobile learning first began in 1994 when Carnegie Mellon University in U.S.carried out a research project named "Wire Andrew", making teachers and students enjoy the convenience of mobile learning and creating a precedent for the research on this field. As a new learning model, there is no unified concept on M-learning. We believe mobile learning involves the use of mobile technology, either alone or in combination with other information and communication technology (ICT), to enable learning anytime and anywhere. It can be formal learning or informal learning (Kukulska \& Shield, 2008). Literature shows that the anytime and anyplace learning opportunity of mobiles provides several benefits for the learning environment like allowing learners and instructors to utilize their spare time while traveling to finish their homework or lesson preparation (Virvou \& Alepis, 2005).

Mobile learning mode is especially suitable for language learning. The earliest studies on applying mobile learning mode in language learning and teaching were carried out by Stanford University in U.S. Subsequently, Duke University and the University of Tokushima in Japan were also conducting research on using mobile technology to assist reading, listening and oral English teaching. The concept of Mobile Assisted Language Learning (MALL) has been put forward to describe an approach to language learning that is assisted or enhanced through the use of a hand-held mobile device.

Late as the start was, research on mobile learning in China has demonstrated a rapid development. The concept of mobile learning was first introduced to China through Desmond Keegan (2000); his report 
"The future of learning---from the digital learning to mobile learning" opened the prelude to China's research on m-learning. Chinese scholar Gui Qingyang (2003) first advocated that after e-learning (Electronic Learning), m-learning is a new form of distance learning and it is the future of China's foreign language learning.

\section{PRESENT SITUATION AND PROBLEMS OF COLLEGE ENGLISH PHONETIC TEACHING}

Pronunciation is an important part of speaking, listening experiences, and an essential cuing system that Second Language learners use along with other kinds of information (Dahl \& Scharer, 2000). Therefore, it is necessary for language teachers to emphasize pronunciation teaching in their classes. However, the following problems still exist:

\subsection{Insufficient Teaching Hours for Phonetics}

There is a de-emphasizing phenomenon for English pronunciation teaching, which is very common in Chinese universities. For example, Phonetics course is usually only for the minority---English majors, while for the majority, the non-English majors; no specific English phonetics lessons are offered. Because phonetics teaching is combined in oral and listening classes and there is insufficient teaching hours for phonetics, non-English majors lack systematical and formal pronunciation training.

\subsection{Unqualified Teachers}

Some teachers are not equipped with accurate and decent English pronunciation. And do not have a good command of phonetic and phonological knowledge and do not know the basic method for pronunciation teaching.

\subsection{Lack of Timely and Effective Individualized Feedback}

Over-crowded classroom often leaves little time and energy for one teacher to pay attention to each student, and the feedback on individuals pronunciation problems is too limited.

\section{PHONETIC LEARNING SOFTWARE BASED ON ANDROID SYSTEM}

The phonetic learning software we adopt is called "English Liulishuo" (http://www.liulishuo.com/), ranking the first and the most popular educational APP in China. In October 2014, its users reached over 730000. With the integration of automatic speech recognition and evaluation technologies, this software provides individualized practices and real- time feedback for learners. Practice content covers various types of scene, such as: daily life, business, tourism and entertainment. Compared with other educational APP, Liulishuo provides more free courses, and updates more frequently.

Five important functions: (1) Instant diagnosis and evaluation of pronunciation and intonation. Learners listen to utterances spoken by speakers from different parts of the world, then learners record their own utterances. Liulishuo can explicitly pinpoint learner's pronunciation errors by giving feedback that compares the learner's pronunciation with the model. A score will be give for each sentence practiced by the learner. When the whole dialogue is finished, a total score will be given for the performance. (2) Courses for different levels. Liulishuo offers courses of three different levels, the elementary, the intermediate and advanced level. A game is waiting, when a training is finished, making learning more interesting and challenging. (3)Scene simulation, cos-play, intelligent human-machine dialogue. The software features a series of English conversation courses, simulating real communication environment. If one need to find a partner to practice, he can always rely on the software. Choose a scene and select a role, one can start to practice pronunciation and oral English. (See Figure1) (4) Quick word access and inquiry system. If one is facing any new words during the training, one can refer to the dictionary carried by the software. Then save it into "vocabulary book" for further reviewing. Liulishuo offers online inquiry. Questions will be answered by excellent mobile learners.

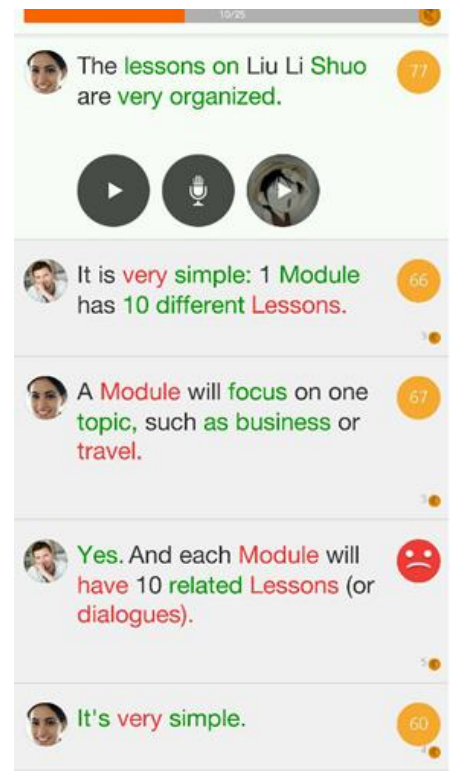

Figure 1. Interface of Speech evaluation, diagnosis

(5) Calculation of the average scores and daily or weekly learning times. This function allows students to send their training results to the teacher's mobile phone through wechat or $Q Q$. Teachers can also use this function to monitor students' training hours and 
giving strategic instruction if necessary. (See Figure2)

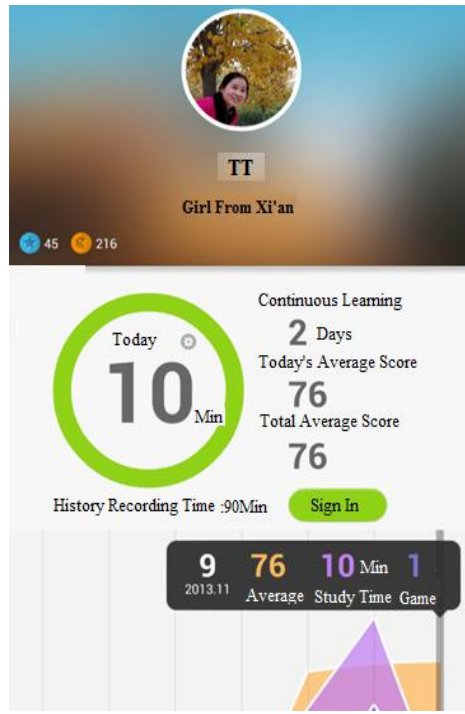

Figure 2. Interface of average scores and learning times

\section{RESEARCH METHOD AND EXPERIMENTAL DESIGN}

\subsection{Subjects}

Sixty-seven freshmen who were non Englishmajored participated. They were divided into two classes, 34 for the experimental class (EC), 33 for the control class (CC). The students had one oral English session per week with the same textbook and the same oral English teacher.

\subsection{Training Procedure}

As no phonetic lesson for non-English majors, traditional phonetic instruction was given within oral classes, 15 minutes each time for 14 weeks. For the CC, students only received traditional phonetic instruction. For the EC, the teacher introduced the concept of mobile learning. In the first session EC students were asked to install the phonetic mobile learning system into their cell phone and instructions were given to make sure every one know how to apply it in their daily practice. The students were required to adopt the system to do mobile learning 0.25 hours each time, 3 times per week for fourteen weeks. And every weekend, they had to send their training times and results to the teacher through Wechat.

\subsection{Research Instrument}

\subsubsection{Phonetic test paper}

A pretest and a post test were conducted. The tests consisted of four parts: 20 English phonemes, 30 English words; 10 sentences; 1 passage. Three scorers were included in the study. They are all experienced oral teachers and examiners for College
English Oral Test.

\subsubsection{Questionnaire}

The questionnaire is divided into two parts. Part 1 contains 10 questions for students attitudes towards phonetic instruction, 15 questions in part 2 for students' knowledge and attitudes towards mobile learning. Unofficial interviews were carried out for interpreting some questionnaire results.

\section{RESULTS AND ANALYSIS}

\subsection{Comparison of Test Results between Two Classes}

Means of the two tests are shown in Table 1. The two classes were basically equivalent in their English phonetic proficiency before the training as their means of the pretest were close (EC: $M=64.35$, $\mathrm{CC}: \mathrm{M}=63.88$ ). Means of the post test (EC: $M=85.71, C C: M=76.52$ ) show that both classes made improvements in phonetic learning after training. However, means of post test for EC is much higher than that of $\mathrm{CC}$. T-test result shows that the scores of the post-test of these two classes are significantly different $(t=4.235, p=0.000<0.05)$. Therefore, we conclude that the EC has outperformed the $\mathrm{CC}$ at the end of the study, which means comparing with traditional phonetic instruction, the pedagogy of integrating mobile learning into traditional phonetic teaching can be more effective in improving students' phonetic level.

Table 1. Means of the two test and T-test for post test

\begin{tabular}{|c|c|c|c|c|c|c|}
\hline & \multicolumn{2}{|c|}{ Pretest } & \multicolumn{2}{c|}{ Post-test } & \multicolumn{2}{c|}{ T-test } \\
\hline $\mathrm{N}=67$ & $\mathrm{M}$ & $\mathrm{SD}_{1}$ & $\mathrm{M}$ & $\mathrm{SD}_{2}$ & $t$ & $p$ \\
\hline $\mathrm{EC}=34$ & 64.35 & 6.332 & 85.71 & 5.824 & & \\
\cline { 1 - 5 } $\mathrm{CC}=33$ & 63.88 & 7.873 & 76.52 & 6.869 & 4.23 & 0.000 \\
\hline
\end{tabular}

\subsection{Comparison of High-scored and Low-scored Students}

In order to see if there are any differences between high-scored and low-scored students in mobile learning, the top 4 students in the post test from EC were labeled high-scored students and the other 4 students with the lowest scores were grouped into Low-scored. By checking the information they sent through Wechat, we find out Higher-scored students tended to practice more in their spare time (9.5 times/week) while the low-scored only practiced 2.75 times per week. (See Table 2.)

Table 2. Mobile learning times of high and low-scored students

\begin{tabular}{|c|c|c|c|}
\hline $\mathrm{N}=8$ & $\begin{array}{c}\text { Means } \\
\text { of Post-test }\end{array}$ & Times/week & Minute/Time \\
\hline High-scored=4 & 92.5 & 9.50 & $21.5 \mathrm{~m}$ \\
\hline Low-scored=4 & 71.5 & 2.75 & $18.5 \mathrm{~m}$ \\
\hline
\end{tabular}




\subsection{Results and Analysis of The Questionnaire}

\subsubsection{Majority holds positive attitudes towards the phonetic training within oral classes.}

98\% students think phonetics are important in learning a foreign language and the traditional classroom phonetic training is necessary and helpful. $78 \%$ students believe their phonetic levels have been improved through systematic phonetic training. The interviews tell us many students even trust phonetic training promoted their phonetic awareness and sense of language.

\subsubsection{With great enthusiasm, but the freshman has a poor understanding on mobile learning.}

Although 95\% students claims to have great interest in mobile learning and $92 \%$ students in EC believes mobile learning helps them a lot in phonetics, but only $45 \%$ students admits that they heard about the term "mobile learning" before coming to college. Through the interviews, we know the prejudice in high school might be the reason. In high school, teachers did not allow students to use mobile devices regarded as a distraction for learning. Therefore we suggest teachers should give a full introduction of mobile learning to first-year students.

\subsubsection{For first-year students, teacher's supervision and instruction are necessary during the process of mobile learning.}

$87 \%$ students from EC agrees that teacher's supervision and monitor are necessary and supportive. The four low-scored students said that teacher's supervision was essentially important for them, as their poor ability for self-management and autonomous learning. Despite its potential to impact learning environment, m-learning is still in early development stages with both technological and pedagogical limitations (Agha \& Ayse, 2011). Therefore, teacher's guidance is indispensable for first-year college students.

\section{CONCLUSION}

Mobile learning improves teaching efficiency and promotes the construction of advanced teaching platform. This paper investigates the effectiveness of mobile learning system on phonetics teaching. Fourteen-week experiment tells combining mobile learning with classroom phonetic teaching enhances students' phonetic awareness and effectively improves phonetic level. The questionnaire reveals that first-year students lack a sufficient knowledge of mobile learning; teachers' instruction and supervision are needed before and during the activities.

\section{ACKNOWLEDGMENTS}

This work is the result of research supported by "China Foreign Language Education Fund" NO. ZGWYJYJJ2014A44.

\section{REFERENCES}

[1] Keegan, D. 2000.The future of learning: from E-learning to M-learning. http://learning.ericsson.net/Leonardo/book.

[2] Kukulska, A. \& Shield, L. 2008. An overview of mobile assisted language learning: From content delivery to supported collaboration and inter-action. ReCALL, 20(3).

[3] Virvou, M. \& Alepis, E. 2005. Mobile educational features in authoring tools for personalized tutoring. Computers and Education 44:53-68.

[4] Gui Q.Y. 2003. M-learning---the future of China's foreign language teaching. Computer-assisted Foreign Language Education

[5] Dahl, K.L \& Scharer, P.L. 2000. Phonetics teaching and learning in whole language classroom: New evidence from research. The Reading Teacher: 53:7.

[6] Agah, T.K. \& Ayse, A. 2011. Differences between mlearning (mobile learning) and e-learning, basic terminology and usage of m-learning in education. Procedia-Social and Behavioral Sciences. 15:1925-1930. 